\title{
Determination the Structural Properties of Polystyrene (Cork) Doped by Aluminium Oxide Using the (XRD) Technique
}

\author{
Tamador Almardi Albashier ${ }^{1}$, Mahmoud Hamid Mahmoud Hilo ${ }^{1,2}$, Abdalsakhi Suliman ${ }^{3}$ \\ ${ }^{1}$ Department of Physics, Faculty of Science, Sudan University of Science and Technology, Khartoum, Sudan \\ ${ }^{2}$ Department of Basic Science, Faculty of Computation, Sudan International University, Khartoum, Sudan \\ ${ }^{3}$ Department of Physics, Faculty of Science, Neilien University, Khartoum, Sudan
}

Email address:

mahmoud1972@sustech.edu (M. H. M. Hilo),mahmoudhilo@gmail.com (M. H. M. Hilo), tamador.almardi@gmail.com (T. A. Albashier)

\section{To cite this article:}

Tamador Almardi Albashier, Mahmoud Hamid Mahmoud Hilo, Abdalsakhi Suliman. Determination the Structural Properties of Polystyrene (Cork) Doped by Aluminium Oxide Using the (XRD) Technique. American Journal of Materials Synthesis and Processing.

Vol. 6, No. 1, 2021, pp. 10-19. doi: 10.11648/j.ajmsp.20210601.12

Received: October 31, 2020; Accepted: November 20, 2020; Published: March 12, 2021

\begin{abstract}
The X-ray diffraction technique is one of the techniques that are widely and precisely used in determining the structural properties of materials through which materials can be developed and their areas of use increased, and Cork is considered one of the polymers of very low industrial value and is used only for secondary purposes such as packaging, and it is possible to have any other uses of high value by doping the cork with materials that can change its physical properties. Therefore, this study aimed to improve the structural properties of cork (polystyrene) doped by aluminum oxide with doping ratios $(0.1, \ldots . ., 0.9)$ molar, through X-ray diffraction, where the results showed that all the prepared samples are multi-crystallized of the types (cubic, mono, triple and hexagonal). And it was found that the preferred direction of growth is the level (211), and the crystal size of all the prepared samples was calculated, and it was found that it increases with the increase in the percentage of doping. Also, the density and number of crystals were calculated as each of them decreases with the increase of the doping percentage. This study concluded that cork, through its structural properties and after doping by aluminum oxide, can be of great technological benefit by having properties that are very similar to those of a semiconductor.
\end{abstract}

Keywords: Cork, Polystyrene, Structural Properties, XRD, Aluminum Oxide, Doping

\section{Introduction}

The cork tree has a remarkable capacity to create suberose tissue from its inner bark. This tissue, formed specifically by the phylogeny of the cork oak (the tissue responsible for the formation of new cells), derives its name from the Latin super (5cork). The life cycle of the Cork oak produces three qualities of supersize tissue virgin cork, reproduction cork from the second strip-ping; and reproduction cork from subsequent strips [1].

Cork is one of the oldest substances known to mankind, a material that is based like a sponge and its origin is plant and is lightweight, and a insulating material also worse against water, sound, heat and electricity, it does not absorb water easily, and it is also characteristic of cork that it bears high pressure, and this substance appeared in the centuries $\mathrm{BC}$ where the barges were made of them, as well as to float fishing nets being a light material floating on the sea surface, and then used as pipe plugs [2-4]. It does not absorb water easily and can be compressed considerably, but returns to its first state after the pressure has subsided. Since the 4th century B.C., people have used corks and the Romans have worn cork sandals, and they have used cork to float shipyards and fishing nets [5-7]. Cork plugs have been made since the 17 th century. The cork is produced after obtaining the outer shell of the cork tree as it contains an outer layer of coarse sand which is brown, and is adjacent to the cork material and attached to the so-called tannic acid, the first step begins with 
the skimming of the outer layer, and the crust is placed in boiling water until the material becomes soft and the acid separates from it, after which it is easy to form a whole slab of cork, and the cork differs in quality and density and then is shipped to be used in industry [11].

\section{Structural Properties}

The structural properties are an important method for studying the crystal structure of layers, and this is done through the use of X-ray diffraction. X-ray diffraction analysis is used to know the nature of the crystal structure and the main crystalline phases, and that is to know the oriented direction of the prepared layers under certain conditions, as the general principle of diffraction depends on the phenomenon of interference that occurs when the movement of a wave is dispersed at a number of centers of atoms and as a result, either interference occurs Constructive or destructive interference.

The English scientist (Bragg) assumed a simple pattern of the crystal structure, by means of which he could know the direction of the X-ray diffraction from the crystal after its fall in practice, and this model states that the different levels that are composed of the crystal atoms can reflect the X-rays $[9,10]$.

$$
n \lambda=2 d \sin \theta
$$

Where (d): the distance between two successive atomic levels and $(\Theta)$ the diffraction angle (n) Integer $(1,2,3 \ldots)$, and $\lambda$ : the X-ray wavelength

As the reflection of Braque occurs only when the wavelength of the incident X-rays through which it is possible to obtain a reflection from a plane that has coordinates smaller or equal to twice the interface distance between two successive crystals, as shown in the figure below, therefore, visible light cannot be used to study the crystal structure, that is, the Braque condition For reflection is $\lambda \leq 2 d_{h k l}$

Lattice constants: Knowing the compositional factors of a substance that depends on the X-ray diffraction spectrum is important in explaining many of the physical properties of the material. Thus the lattice constant (a) can be calculated using the following equation

$$
d_{h k l}=\frac{a}{\left(h^{2}+k^{2}+l^{2}\right)^{\frac{1}{2}}}
$$

Average particle size: The average grain size is calculated using the (Scherer's Formula)

$$
D_{a v}=\frac{k \lambda}{\beta \cos \theta}
$$

Since k: the forming factor equals 0.94

$\lambda$ : The wavelength of the X-ray used

$\theta$ : Bragg diffraction angle

$\beta$ : Full width at half-maximum in (rad) (FWHM)

\section{Experimental}

This part of the work includes a detailed description of the preparation of Aluminum Oxide $\left(\mathrm{Al}_{2} \mathrm{O}_{3}\right)$, which is used to dope polystyrene (cork) dissolved in Benzene by the method of Sol-Gel method with volumetric ratios $(0.1$, to 0.9$)$ mol with increasing step of 0.1 at a temperature Chamber by magnetic stirrer to obtain nine samples of doped polystyrene, and then studying the structural and optical properties of the samples by means of X-ray diffraction devices, a UV scale and an infrared device.

\subsection{The Sol-Gel Method}

The sol-gel system consists of several locally available tools through which polystyrene can be doped, these are:

1- Magnetic stirrer and hot plate

2- Holders

3- Thermometers

4- Beakers

5- Sensitive balance

\subsection{Preparation of Aluminum Oxide}

For the preparation of Aluminum oxide, aluminum nitrate $\left(\mathrm{AL}\left(\mathrm{NO}_{3}\right)_{3} 9 \mathrm{H}_{2} \mathrm{O}\right)$ ) was used (as a source of Aluminum oxide, provided by (LOBA CHEMIE) company, with a molecular weight of 375.13 and a concentration of $98 \%$, which is a white powder that is soluble in water, it was prepared at a temperature of (80) degrees Celsius for each Samples with different concentrations ranging from $(0.1,0.2,0.3,0.4,0.5,0.6,0.7,0.8$, 0.9 ) morality by adding $\mathrm{N}, \mathrm{N}$ - Dimethylformamide for HPLC and Spectroscopy as an oxidizing agent and precipitant, and through the following equations:

$$
\begin{gathered}
A L\left(\mathrm{NO}_{3}\right)_{3} 9 \mathrm{H}_{2} \mathrm{O}+\mathrm{H}_{2} \mathrm{O} \stackrel{\Delta}{\longrightarrow} \mathrm{AL}_{2} \mathrm{O}_{3}+\mathrm{H}_{2} \mathrm{O} \\
W_{t}=\frac{M_{w t} * V * M_{\mathrm{O}}}{1000}
\end{gathered}
$$

Where

$\left(M_{\mathrm{O}}\right)$ Denotes the molecular concentration

$\left(W_{t}\right)$ Denotes the solution weight

$\left(M_{w t}\right)$ Denotes the molecular weight

$(V)$ Denotes the volume of distilled water in $(\mathrm{mL})$

A $(773 \mathrm{mg})$ was dissolved in $(69 \mathrm{~mL})$ of distilled water and placed in the magnetic stirrer at a temperature of $80^{\circ} \mathrm{C}$ for 60 minutes, to obtain complete dissolution for the first sample, and then dissolve $(740 \mathrm{mg})$ in $(66.5 \mathrm{~mL})$ of distilled water and placed in the magnetic stirrer at a temperature of $80^{\circ} \mathrm{C}$ for 60 minutes to get the second sample. Also, (804 mg) was dissolved in $(75 \mathrm{~mL})$ of distilled water and placed in the magnetic stirrer at a temperature of 80 for 60 minutes to get the third sample, $(761 \mathrm{mg})$ was dissolved in $(68.5 \mathrm{~mL})$ of distilled water and placed in the magnetic stirrer at a temperature of $80^{\circ} \mathrm{C}$ for 60 minutes to obtain the fourth sample, then, $(801 \mathrm{mg})$ was dissolved in $(70 \mathrm{~mL})$ of distilled 
water and placed in a magnetic stirrer at a temperature of $80^{\circ} \mathrm{C}$ for 60 minutes to obtain the fifth sample, and $(845 \mathrm{mg})$ was dissolved in $(79 \mathrm{~mL})$ of distilled water and placed in the magnetic stirrer at a temperature of $80^{\circ} \mathrm{C}$ for 60 minutes to obtain the sixth sample, $(744 \mathrm{mg})$ was dissolved in $(66 \mathrm{~mL})$ of distilled water and placed in a magnetic stirrer at a temperature of 80 for 60 minutes to obtain the seventh sample, and finally a $(969 \mathrm{mg})$ was dissolved in $(87 \mathrm{~mL})$ of distilled water and placed in a magnetic stirrer at a temperature of $80^{\circ} \mathrm{C}$ for 60 minutes to obtain the eighth sample, and $(840 \mathrm{mg})$ was dissolved in $(74 \mathrm{~mL})$ of distilled water and placed in a magnetic stirrer at a temperature of $80^{\circ} \mathrm{C}$ for 60 minutes to obtain the ninth sample.

Meanwhile, ten samples of the synthetic white cork (polystyrene) that was obtained after use (the waste) was dissolved in laboratory Benzene with a weight of 200 grams for each sample to become a solution and ten samples were prepared, to prepare doped cork samples, each of the nine previously prepared samples was added to a sample of 200 grams of cork dissolved in benzene and placed in the magnetic stirrer for 60 minutes to obtain the nine samples of the gelatinous solution of the cork doped by Aluminum oxide, then the solutions were placed in the bakers with the magnetic stirrer for 60 minutes to complete mixing and that to obtain a gelatinous solution. Spread it on glass slides, then leave the samples for 24 hours to dry and ready for testing.

\section{Results and Discussion}

In this part of the paper, first the main comparison with pervious works shows that, Comparing this to the work [12, 13] which intended that the mechanical properties of the Cork is affected by the doping with PTT-g-MA which is the way that the doping by aluminum oxide did in our work, then the main results that have been obtained from the experiments made of polystyrene (cork) doped by aluminum oxide in different rate of molar $(0.1,0.2,0.3,0.4,0.5,0.6$, $0.7,0.8,0.9$ and 1.0 ) are presented, the techniques of X-ray diffraction (XRD) was used to identify the precise crystal structure of the samples, where an X-ray was shed on the samples, which would appear according to reflections (Bragg) representing the atoms arranged in a specific direction, and through the data obtained from the tests of the prepared samples, the granular size, lattice constants and density can be calculated, and macroscopic compliance, and the specifications of the X-ray diffraction device that was used at the University of Johannesburg - South Africa are as follows:

Type: XRD- 6000 Shimadzu

Target: $\mathrm{Cu}-\mathrm{K} \alpha$

Wave Length: $1.54060^{\circ} \mathrm{A}$

Speed: $5 \mathrm{deg} / \mathrm{min}$

Current: $30 \mathrm{~mA}$

Voltage: $40 \mathrm{KV}$

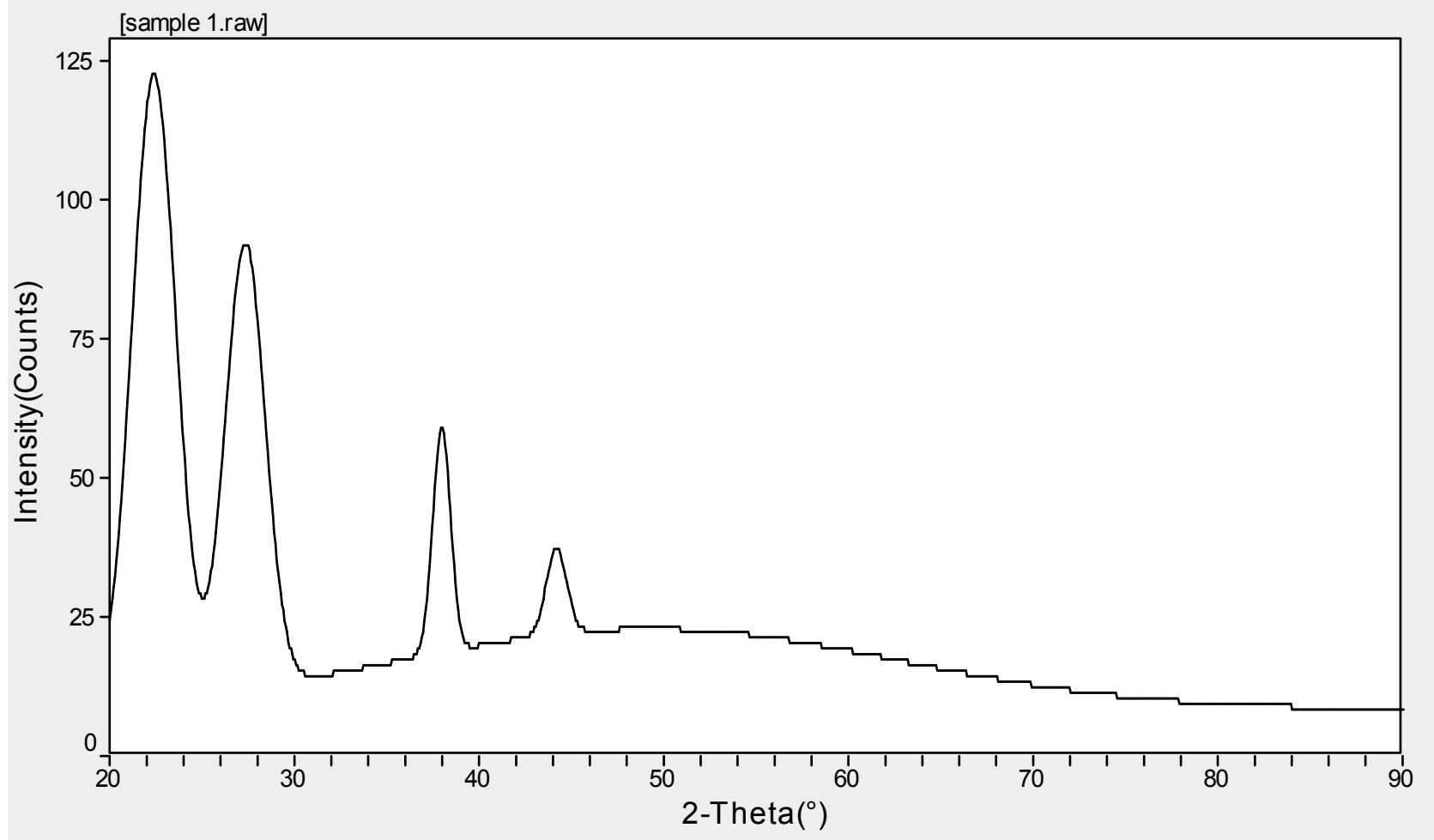

Figure 1. XRD spectrum of sample 1. 
Table 1. Calculated Lattice Constants from Peak Locations and Miller Indices [Monoclinic] of sample 1.

\begin{tabular}{llllll}
\hline $\mathbf{2 \theta}$ & $\mathbf{d}(\mathbf{n m})$ & $\mathbf{H}$ & $\mathbf{k}$ & $\mathbf{l}$ & $\mathbf{X}_{\mathbf{s}}(\mathbf{n m})$ \\
\hline 22.869 & 3.8855 & 3 & 1 & 1 & 6.2 \\
27.781 & 3.2086 & 4 & 1 & 1 & 15.2 \\
37.974 & 2.3675 & 1 & 3 & 0 & 9.9 \\
\hline
\end{tabular}

Cell Volume $=123.3\left(\mathrm{~A}^{\mathrm{O}}\right)^{3}$

$\mathrm{a}=10.277 \mathrm{~b}=12.66 \mathrm{c}=10.629$

$\alpha=90^{\circ} \beta=116.82^{\circ} \gamma=90^{\circ}$

Density $=7.8117 \mathrm{mg} \cdot \mathrm{cm}^{-3}$

Crystal Form: Monoclinic - Primitive
Table 2. Calculate Lattice Constants from Peak Locations and Miller Indices [Tetragonal] of sample 2.

\begin{tabular}{llllll}
\hline $\mathbf{2 \theta}$ & $\mathbf{d}(\mathbf{n m})$ & $\mathbf{H}$ & $\mathbf{k}$ & $\mathbf{l}$ & $\mathbf{X}_{\mathbf{s}}(\mathbf{n m})$ \\
\hline 39.21 & 22.957 & 1 & 1 & 2 & 14.3 \\
\hline
\end{tabular}

Cell Volume $=126.3\left(\mathrm{~A}^{\mathrm{O}}\right)^{3}$

$\mathrm{a}=\mathrm{b}=3.842 \mathrm{c}=8.553$

$\alpha=\beta=\gamma=90^{\circ}$

Density $=6.8865 \mathrm{mg} \cdot \mathrm{cm}^{-3}$

Crystal Form: Tetragonal - I- Center

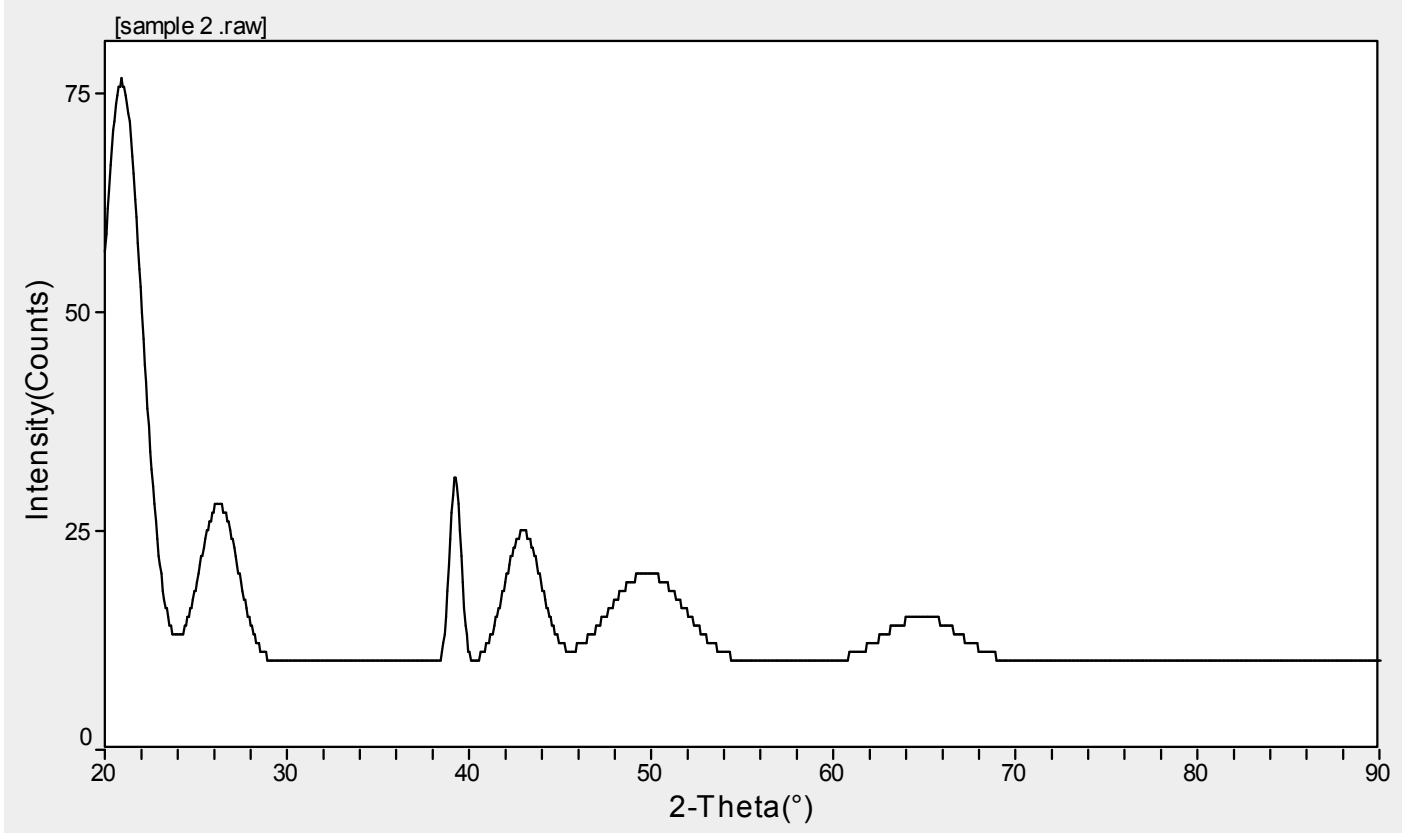

Figure 2. XRD spectrum of sample 2.

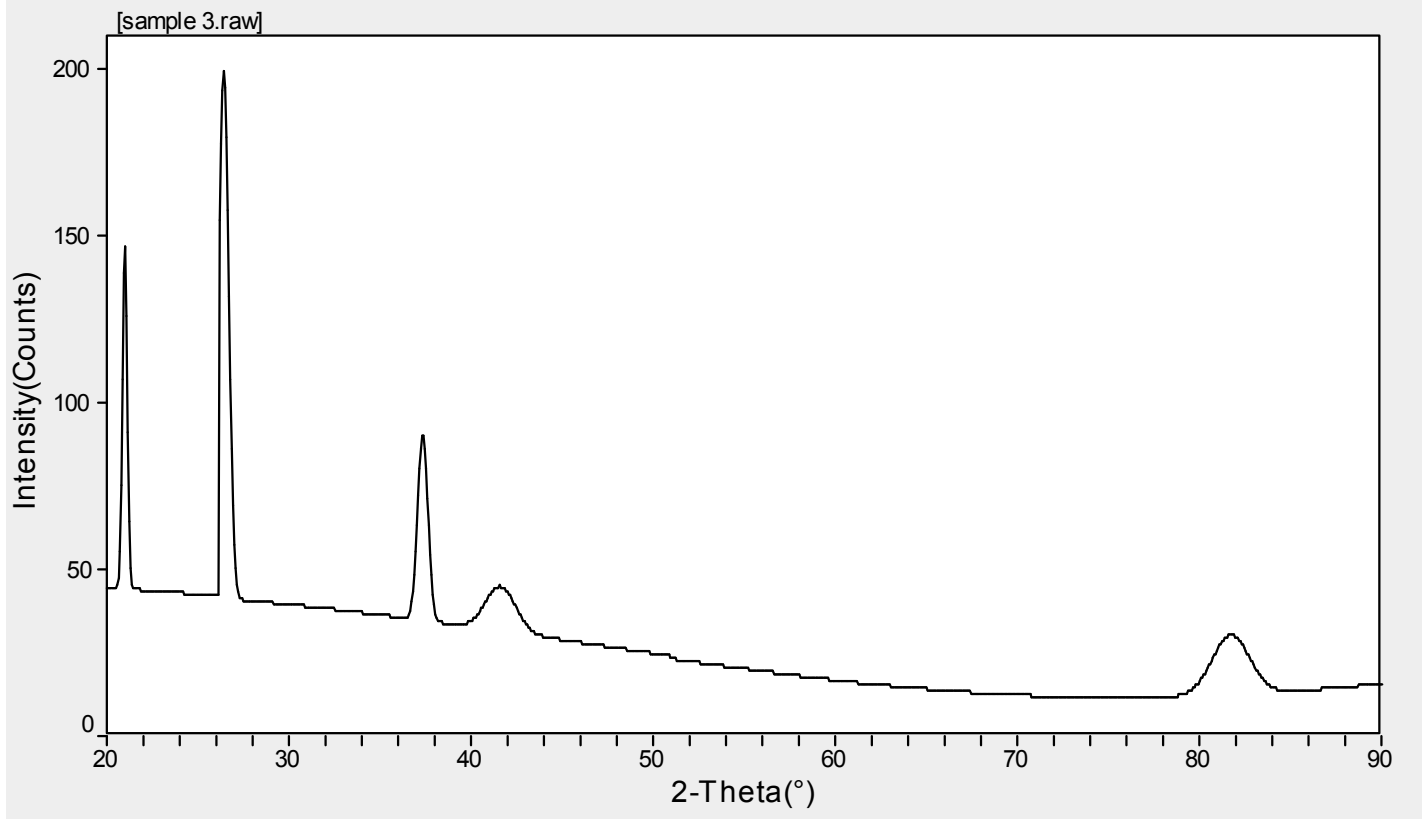

Figure 3. XRD spectrum of sample 3. 
Table 3. Calculate Lattice Constants from Peak Locations and Miller Indices [Monoclinic] of sample 3.

\begin{tabular}{llllll}
\hline $\mathbf{2 \theta}$ & $\mathbf{d}(\mathbf{n m})$ & $\mathbf{H}$ & $\mathbf{k}$ & $\mathbf{l}$ & $\mathbf{X}_{\mathbf{s}}(\mathbf{n m})$ \\
\hline 20.972 & 4.2325 & 0 & 0 & 2 & 30.2 \\
26.324 & 3.3828 & 2 & 1 & 1 & 18.3 \\
37.363 & 2.4048 & 3 & 1 & 1 & 14.7 \\
\hline
\end{tabular}

Cell Volume $=492\left(\mathrm{~A}^{\mathrm{O}}\right)^{3}$

$\mathrm{a}=7.605 \mathrm{~b}=7.754 \mathrm{c}=8.627$

$\alpha=90^{\circ} \beta=104.6^{\circ} \gamma=90^{\circ}$

Density $=5.2817 \mathrm{mg} \cdot \mathrm{cm}^{-3}$

Crystal Form: Monoclinic- Primitive
Table 4. Calculate Lattice Constants from Peak Locations and Miller Indices [Triclinic] of sample 4.

\begin{tabular}{llllll}
\hline $\mathbf{2 \theta}$ & $\mathbf{d}(\mathbf{n m})$ & $\mathbf{H}$ & $\mathbf{k}$ & $\mathbf{l}$ & $\left.\mathbf{X}_{\mathbf{s}} \mathbf{( n m}\right)$ \\
\hline 21.14 & 4.1911 & 1 & 1 & 2 & 12.6 \\
23.734 & 3.47458 & 0 & 2 & 3 & 8.0 \\
38.022 & 2.3646 & 1 & 3 & 3 & 12.3 \\
\hline
\end{tabular}

Cell Volume $=540.6\left(\mathrm{~A}^{\mathrm{O}}\right)^{3}$

$\mathrm{a}=6.9804 \mathrm{~b}=8.7402 \mathrm{c}=10.283$

$\alpha=107.702^{\circ} \beta=105.269^{\circ} \gamma=103.881^{\mathrm{O}}$

Density $=4.997 \mathrm{mg} . \mathrm{cm}^{-3}$

Crystal Form: Triclinic - Primitive

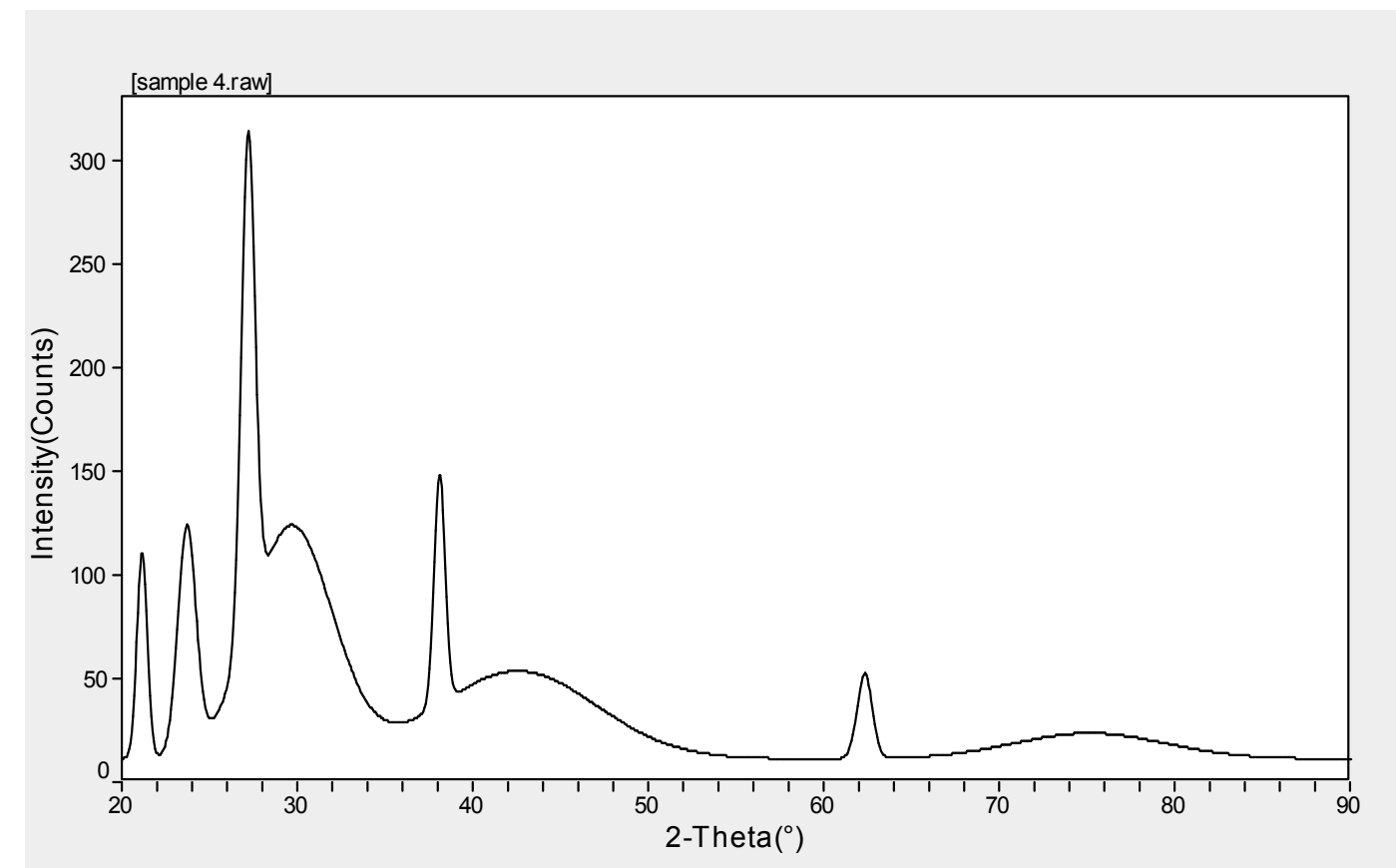

Figure 4. XRD spectrum of sample 4.

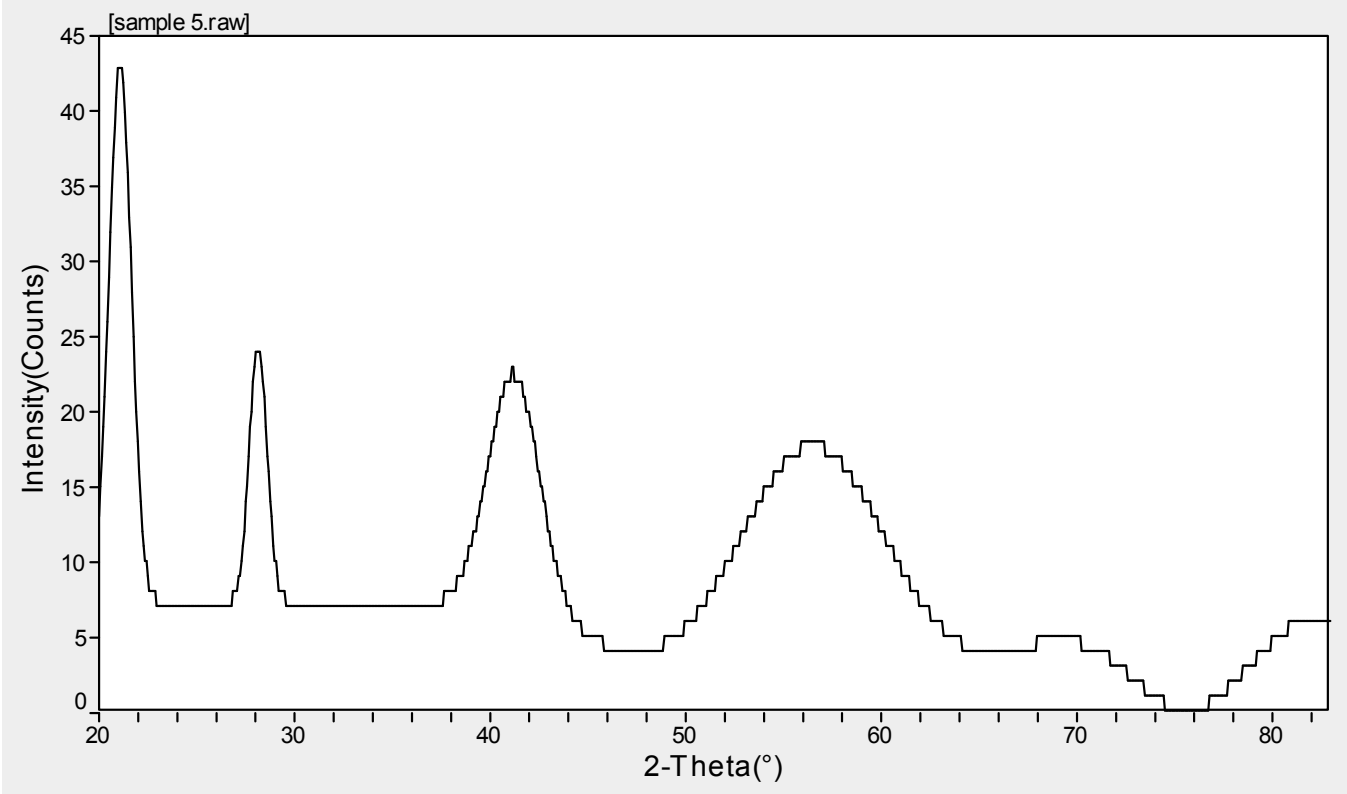

Figure 5. XRD spectrum of sample 5. 
Table 5. Calculate Lattice Constants from Peak Locations and Miller Indices [Monoclinic] of sample 5.

\begin{tabular}{llllll}
\hline $\mathbf{2 \theta}$ & $\mathbf{d}(\mathbf{n m})$ & $\mathbf{H}$ & $\mathbf{k}$ & $\mathbf{l}$ & $\mathbf{X}_{\mathbf{s}}(\mathbf{n m})$ \\
\hline 21.037 & 4.2194 & 1 & 2 & 1 & 8.1 \\
\hline
\end{tabular}

Cell Volume $=1126.2\left(\mathrm{~A}^{\mathrm{O}}\right)^{3}$

$\mathrm{a}=7.353 \mathrm{~b}=25.225 \mathrm{c}=6.097$

$\alpha=90^{\circ} \beta=95.2^{\mathrm{O}} \gamma=90^{\circ}$

Density $=4.0653 \mathrm{mg} . \mathrm{cm}^{-3}$

Crystal Form: Monoclinic - Primitive
Table 6. Calculate Lattice Constants from Peak Locations and Miller Indices [Hexagonal] of sample 6.

\begin{tabular}{llllll}
\hline $\mathbf{2 \theta}$ & $\mathbf{d}(\mathbf{n m})$ & $\mathbf{H}$ & $\mathbf{k}$ & $\mathbf{l}$ & $\mathbf{X}_{\mathbf{s}}(\mathbf{n m})$ \\
\hline 22.321 & 3.9795 & 2 & 1 & 1 & 7.7 \\
\hline
\end{tabular}

Cell Volume $=1385.5\left(\mathrm{~A}^{\mathrm{O}}\right)^{3}$

$\mathrm{a}=13.74 \mathrm{~b}=13.74 \mathrm{c}=8.474$

$\alpha=90^{\circ} \beta=90^{\circ} \gamma=120^{\circ}$

Density $=4.0001 \mathrm{mg} \cdot \mathrm{cm}^{-3}$

Crystal Form: Hexagonal - Primitive

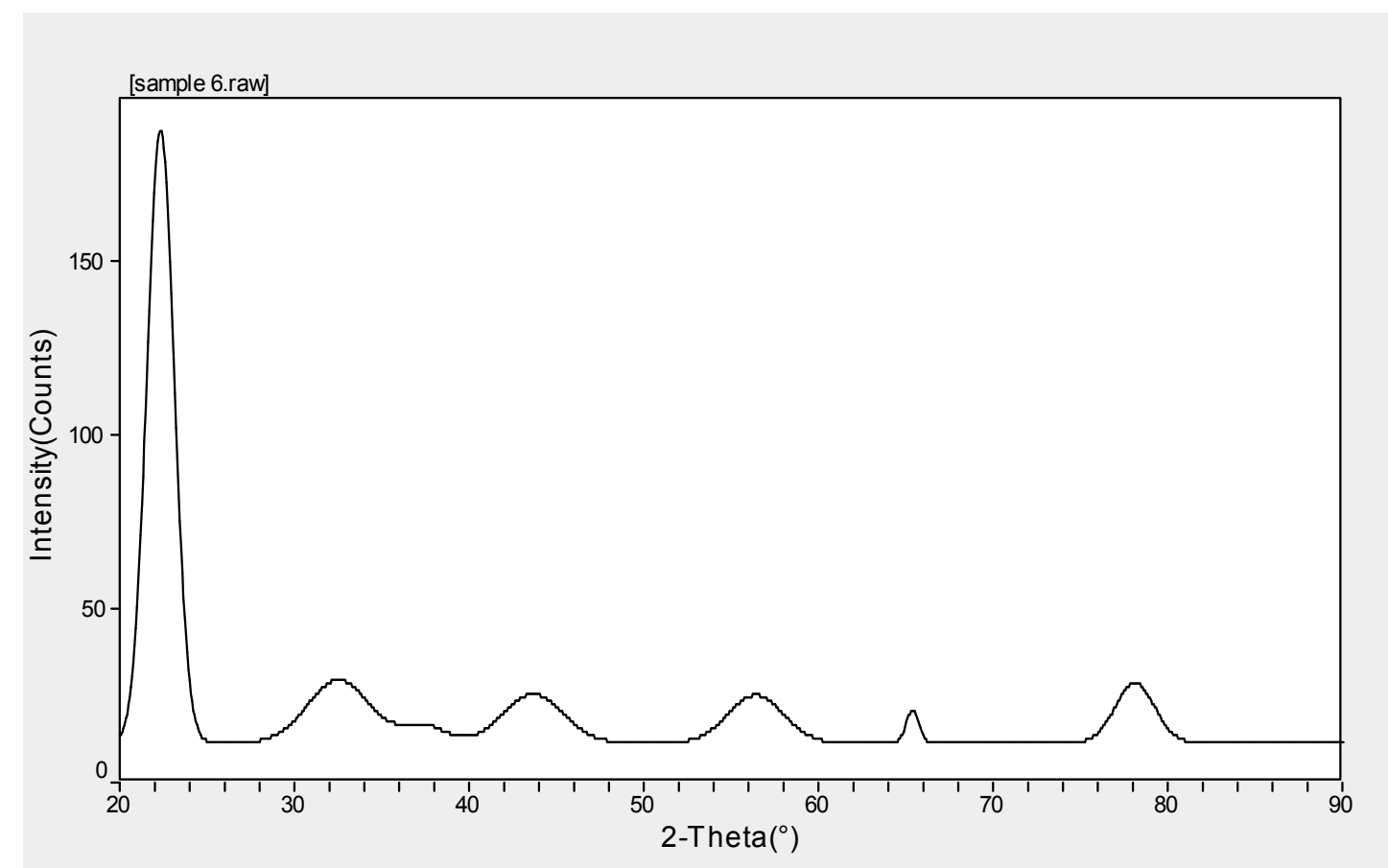

Figure 6. XRD spectrum of sample 6.

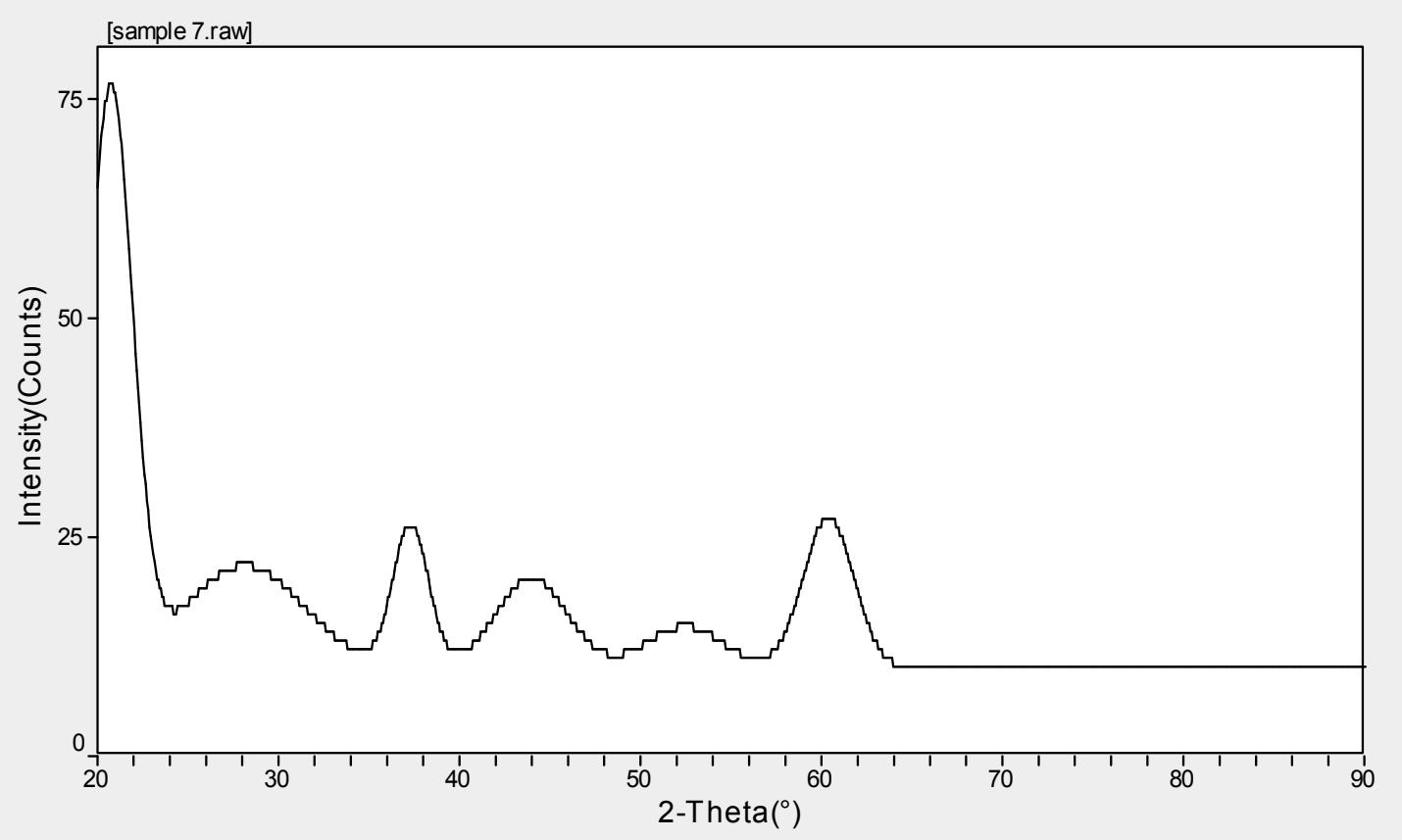

Figure 7. XRD spectrum of sample 7. 
Table 7. Calculate Lattice Constants from Peak Locations and Miller Indices [Hexagonal] of sample 7.

\begin{tabular}{llllll}
\hline $\mathbf{2 \theta}$ & $\mathbf{d}(\mathbf{n m})$ & $\mathbf{H}$ & $\mathbf{k}$ & $\mathbf{l}$ & $\left.\mathbf{X}_{\mathbf{s}} \mathbf{( n m}\right)$ \\
\hline 22.321 & 3.9795 & 2 & 1 & 1 & 7.7 \\
\hline
\end{tabular}

Cell Volume $=1385.5\left(\mathrm{~A}^{\mathrm{O}}\right)^{3}$

$\mathrm{a}=13.74 \mathrm{~b}=13.74 \mathrm{c}=8.474$

$\alpha=90^{\circ} \beta=90^{\circ} \gamma=120^{\circ}$

Density $=4.0001 \mathrm{mg} \cdot \mathrm{cm}^{-3}$

Crystal Form: Hexagonal - Primitive
Table 8. Calculate Lattice Constants from Peak Locations and Miller Indices [Orthorhombic] of sample 8.

\begin{tabular}{llllll}
\hline $\mathbf{2 \theta}$ & $\mathbf{d}(\mathbf{n m})$ & $\mathbf{H}$ & $\mathbf{k}$ & $\mathbf{l}$ & $\mathbf{X}_{\mathbf{s}}(\mathbf{n m})$ \\
\hline 39.65 & 2.2713 & 0 & 2 & 3 & 12.9 \\
\hline
\end{tabular}

Cell Volume $=613.4\left(\mathrm{~A}^{\mathrm{O}}\right)^{3}$

$\mathrm{a}=5.9436 \mathrm{~b}=14.433 \mathrm{c}=7.1508$

$\alpha=90^{\circ} \beta=90^{\circ} \gamma=90^{\circ}$

Density $=3.5508 \mathrm{mg} \cdot \mathrm{cm}^{-3}$

Crystal Form: Orthorhombic - C-Center

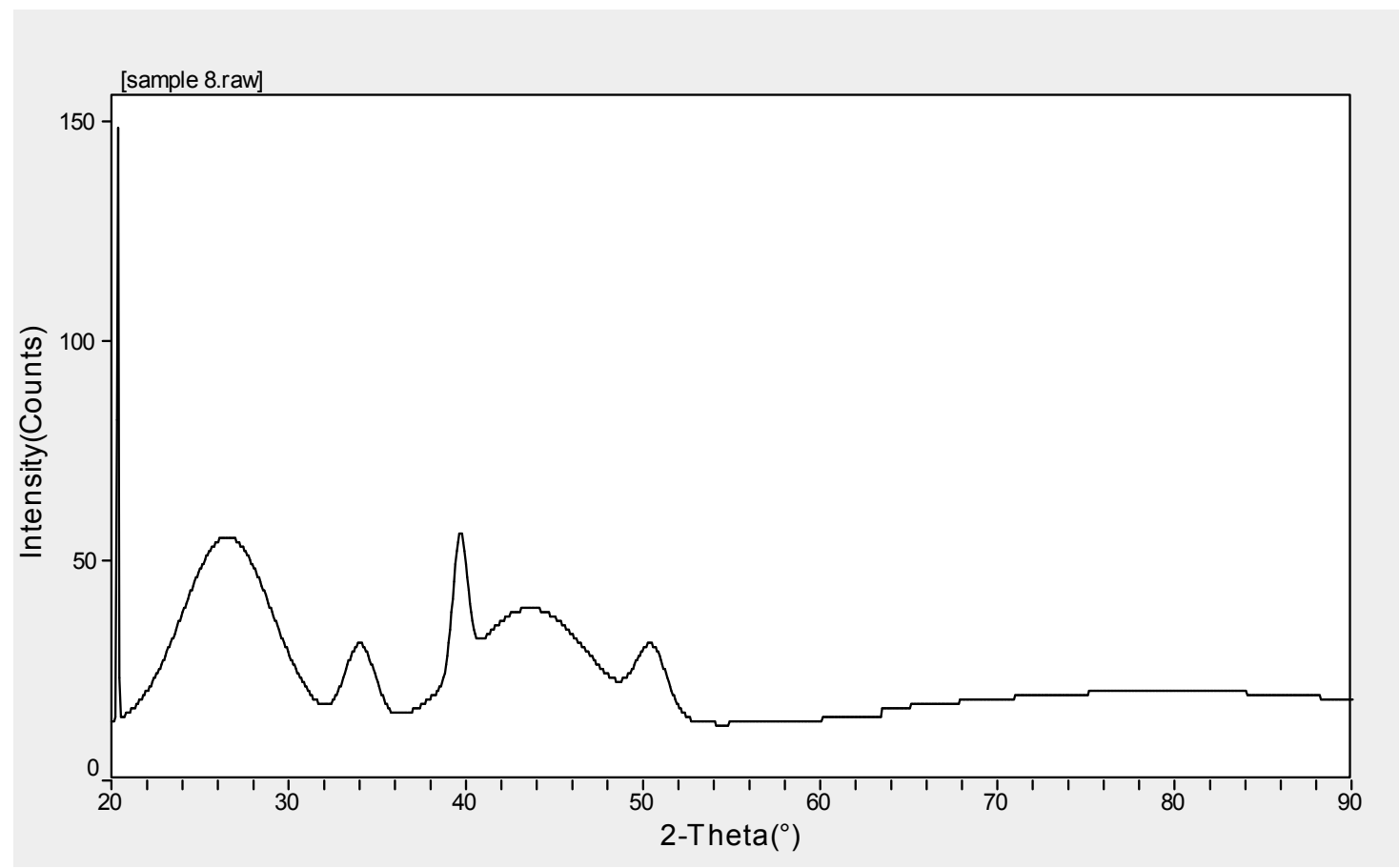

Figure 8. XRD spectrum of sample 8.

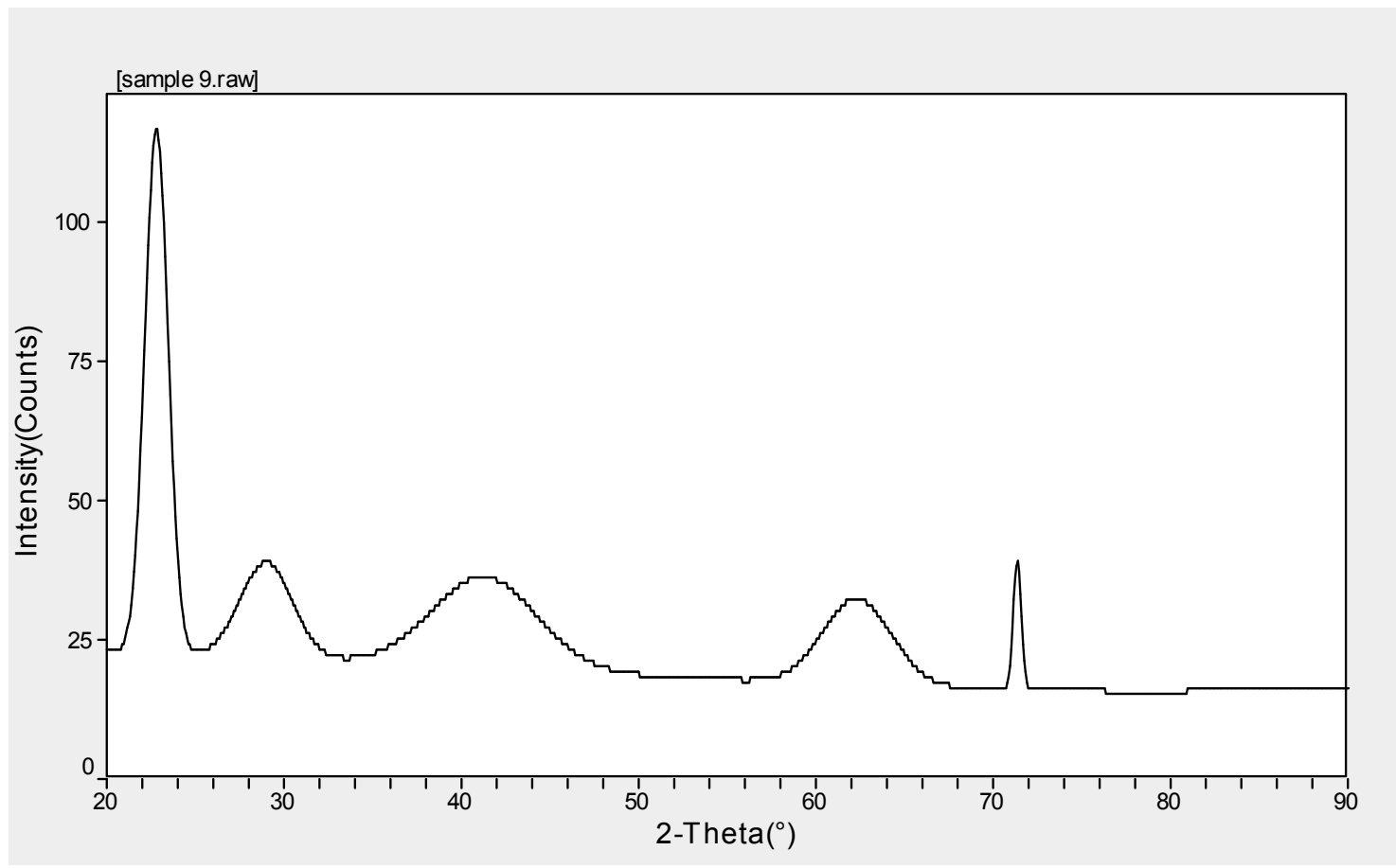

Figure 9. XRD spectrum of sample 9. 
Table 9. Calculate Lattice Constants from Peak Locations and Miller Indices [Monoclinic] of sample 9.

\begin{tabular}{llllll}
\hline $\mathbf{2 \theta}$ & $\mathbf{d}(\mathbf{n m})$ & $\mathbf{H}$ & $\mathbf{k}$ & $\mathbf{l}$ & $\mathbf{X}_{\mathbf{s}}(\mathbf{n m})$ \\
\hline 22.764 & 3.9031 & 2 & 2 & 2 & 6.4 \\
73.44 & 1.3208 & 1 & 5 & 0 & 20 \\
\hline
\end{tabular}

Cell Volume $=22594.9\left(\mathrm{~A}^{\mathrm{O}}\right)^{3}$

$\mathrm{a}=14.044 \mathrm{~b}=13.812 \mathrm{c}=13.382$

$\alpha=90^{\circ} \beta=91.48^{\circ} \gamma=90^{\circ}$ Density $=2.3003 \mathrm{mg} \cdot \mathrm{cm}^{-3}$

Crystal Form: Monoclinic - Primitive
Table 10. Calculate Lattice Constants from Peak Locations and Miller Indices [Monoclinic] of sample 10.

\begin{tabular}{llllll}
\hline $\mathbf{2 \theta}$ & $\mathbf{d}(\mathbf{n m})$ & $\mathbf{H}$ & $\mathbf{k}$ & $\mathbf{l}$ & $\left.\mathbf{X}_{\mathbf{s}} \mathbf{( n m}\right)$ \\
\hline 21.295 & 4.1689 & 0 & 2 & 0 & 7.6 \\
27.358 & 3.2572 & 2 & 1 & 1 & 6.3 \\
\hline
\end{tabular}

Cell Volume $=492.5\left(\mathrm{~A}^{0}\right)^{3} \mathrm{a}=11.045 \mathrm{~b}=8.193 \mathrm{c}=5.535$

$\alpha=90^{\circ} \beta=100.5^{\circ} \gamma=90^{\circ}$ Density $=1.4873 \mathrm{mg} \cdot \mathrm{cm}^{-3}$

Crystal Form: Monoclinic - Primitive

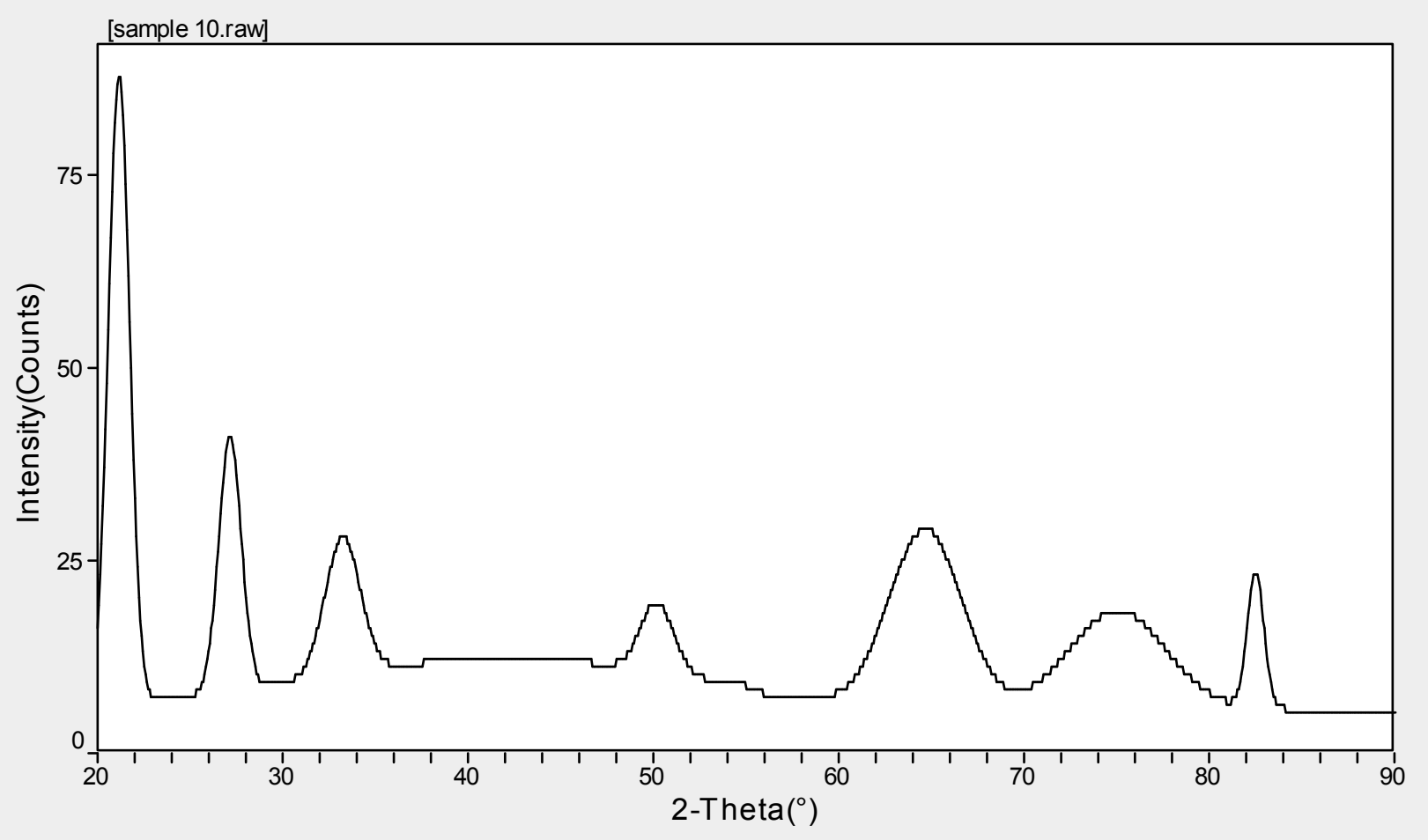

Figure 10. XRD spectrum of sample 10.

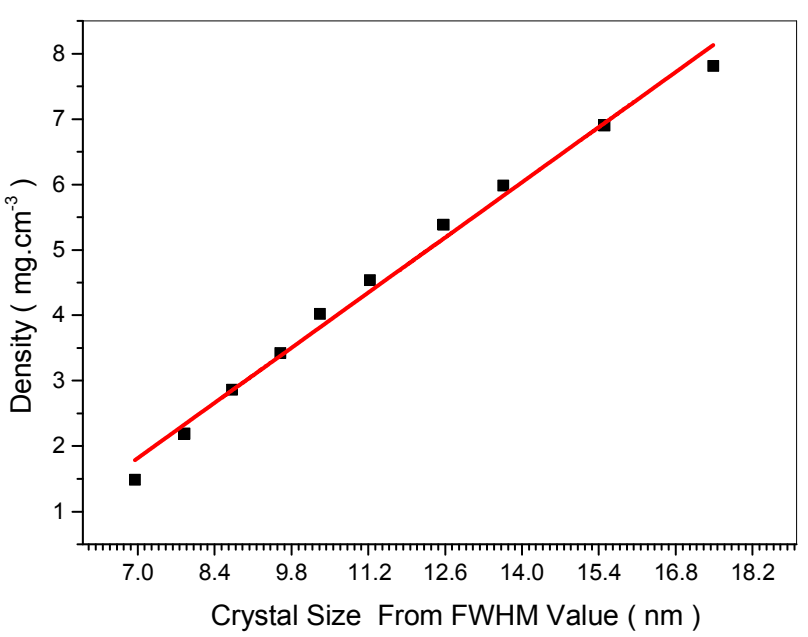

Figure 11. Relation sheep between Crystal size and density of polystyrene (cork) doping by aluminum oxide in different rate of molar (0.1, 0.2, 0.3, 0.4, 0.5, 0.6, 0.7, 0.8, 0.9 and 1.0) Molar samples

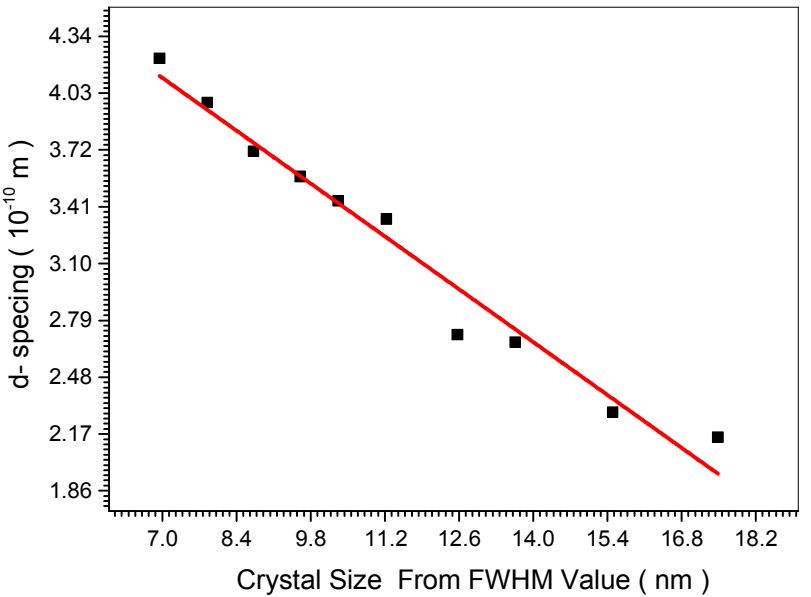

Figure 12. Relation sheep between Crystal size and $d$ - spacing of polystyrene (cork) doping by aluminum oxide in different rate of molar (0.1, $0.2,0.3,0.4,0.5,0.6,0.7,0.8,0.9$ and 1.0) Molar samples. 
Table 11. Some crystallite lattice parameter (c-form, density, Xs (nm) and d-spacing) of polystyrene (cork) doping by aluminum oxide samples.

\begin{tabular}{|c|c|c|c|c|c|}
\hline No & Crystal Form & Density $\left(\mathrm{mg} \mathrm{cm}^{-3}\right)$ & Cell Volume $\left(A^{0}\right)^{3}$ & d ( nm ) & $\mathrm{X}_{\mathrm{s}}(\mathrm{nm})$ \\
\hline 1 & Monoclinic-Primitive & 7.8117 & 123.3 & 2.15386 & 17.483 \\
\hline 2 & Tetragonal-I- Center & 6.90469 & 126.3 & 2.29 & 15.501 \\
\hline 3 & Monoclinic- Primitive & 5.9817 & 492 & 2.6713 & 13.66 \\
\hline 4 & Triclinic - Primitive & 5.38433 & 540.6 & 2.7119 & 12.57 \\
\hline 5 & Monoclinic- Primitive & 4.53865 & 1126.2 & 3.343 & 11.23 \\
\hline 6 & Hexagonal- Primitive & 4.01859 & 1385.5 & 3.443 & 10.32 \\
\hline 7 & Hexagonal- Primitive & 3.42123 & 1385.5 & 3.575 & 9.599 \\
\hline 8 & Orthorhombic-C-Center & 2.86369 & 613.4 & 3.713 & 8.72 \\
\hline 9 & Monoclinic- Primitive & 2.18902 & 22594.9 & 3.9795 & 7.85 \\
\hline 10 & Monoclinic- Primitive & 1.4873 & 492.5 & 4.2194 & 6.95 \\
\hline
\end{tabular}

The crystal structure of all samples characterized at room temperature using a Philips PW1700 X-ray diffractometer (operated at $40 \mathrm{kV}$ and current of $30 \mathrm{~mA}$ ) and samples were scanned between $20^{\circ}$ and $90^{\circ}$ at a scanning speed of $0.06^{\circ} \mathrm{C} / \mathrm{s}$ using $\mathrm{Cu} \mathrm{K} \alpha$ radiation with $\lambda=1.5418 \AA$. The representative XRD charts of all polystyrene (cork) doped by aluminum oxide in different rate of molar $(0.1,0.2,0.3,0.4,0.5,0.6,0.7$, $0.8,0.9$ and 1.0) as show in Figure 1 to Figure 12. Miller indices provided in the figure and all peaks determine transformation of polystyrene (cork) doped by aluminum oxide in different rate of molar crystallites with tetragonal retile crystal structure. Table 1 to table 11 shows the XRD parameters of polystyrene (cork) doped by aluminum oxide at various crystalline orientations. Figure 11 describes the relation between the Crystal size of polystyrene (cork) doped by aluminum oxide samples and density of samples, it showed that increasing the density of samples increases the Crystal size samples at rate $0.60234 \mathrm{mg}$. $\mathrm{Cm}-3 / \mathrm{nm}$. The dislocation density ( $\delta)$ and number of unit cells (n) of polystyrene (cork) doped by aluminum oxide in different rate of molar is calculated and listed in table 11. Dislocation density decreases by number of unit cells by increasing growth, and decreasing the defects in crystallites. Finally, Figure 12 describes the relation between the Crystal size of polystyrene (cork) doped by aluminum oxide samples and d- spacing of polystyrene (cork) doped by aluminum oxide in different rate of molar, and noticed that the rate of decreasing in the d- spacing of polystyrene (cork) doped by aluminum oxide samples with increases the Crystal size is equal to $0.2061 \times 10^{-10} \mathrm{~m} / \mathrm{nm}$.

\section{Conclusion}

This study concluded that cork as a material of industrial low value can be transformed into a material of effective industrial value by doping it with aluminum oxide and studying its structural properties, so as to improve its structural, electrical, and conducting properties. And since it is considered a cheap industrial and commercial waste and can be obtained easily, and its abundance and development of its properties could make it a good alternative in the industry to some rare and unavailable semiconductors. It can be a good addition in the field of industry of electronic devices such as diodes, transistors and integrated circuits, as well as the possibility of using it in solar cells.

\section{Recommendations}

1. Conducting the same study taking into account the change in the measurement of the thickness of samples in the nano scale boundaries by a fixed amount and noting the extent of this effect.

2. Conduct the same study, taking into account the determination of the amount of solvent (benzene) for the cork material, and it shall be fixed for all samples.

3. Study the possibility of deforming the cork with a material other than metal oxides and knowing the extent of this effect on the structural properties.

\section{References}

[1] A. Barberis; S. Dettori and M. R. Filiggheddu: J. Arid Environ., 2003, 54, 565-569.

[2] C. Fialho, F. Lopes and H. Pereira: For. Ecol. Manage., 2001, 141, 251-258.

[3] M. I. d. F. Carrasquinho: Boletim do Instituto dos Produtos Florestais - Cortic, a, 1987, 583, 17-18.

[4] H. Pereira, M. E. Rosa and M. A. Fortes: IAWA Bull., 1987, 8 (3), 213-217.

[5] A. Costa, H. Pereira and A. Oliveira: For. Ecol. Manage., 2003, 175, 239-246.

[6] M. Maa taoui, H. Espagnac and N. Michaux-Ferriere: Ann. Bot., 1990, 66, 183-190.

[7] S. Ben, "Solid State Electronic Devices", Hall International, Inc., U.S.A, (1990).

[8] M. Fox, "Optical Properties Of Solide", Oxford University Press Inc, New York, (2001).

[9] Y. N. Al-Jammal, "Solid State Physics", Al-Mousal University Press, Arabic Version, (1990).

[10] B. E. Warren, "X-RAY diffraction" Published by Courier Dover, (1990).

[11] Sura N. T., "Study The Structural, optical and electrical properties of Indiumdoped Tinoxide thin films deposited by the rmalevaporation", M.Sc. Thesis, kufa University, (2017). 
[12] Natalia Ferreira Braga (2020), et al, 'Effect of Carbon Nanotubes (CNT) Functionalization and Maleic AnhydrideGrafted Poly (trim ethyleneterephthalate) (PTT-g-MA) on the Preparation ofAntistatic Packages of PTT/CNT Nanocomposites', Federal University of São Paulo (UNIFESP), 330 Talim, São José dos Campos SP 12231-280, Brazil.
[13] Senthilkumar S, Rajendran A. Synthesis, characterization and electrical properties of nano metal and metal-oxide doped with conducting polymer composites by in-situ chemical polymerization. MOJ Poly Sci. 2017; 1 (6): 192-195. DOI: 10.15406/mojps.2017.01.00031. 